\title{
Serum Lipoprotein Abnormalities in Patients with Ischaemic Heart Disease: Comparisons with a Control Population
}

\author{
B. LEWIS, A. CHAIT, \\ C. M. O. OAKLEY, \\ I. D. P. WOOTTON, \\ D. M. KRIKLER, \\ A. ONITIRI, \\ G. SIGURDSSON, A. FEBRUARY
}

British Medical fournal, 1974, 3, 489-493

\section{Summary}

The frequency and nature of abnormalities of serum lipoproteins have been studied, using quantitative techniques, in 143 patients with ischaemic heart disease (I.H.D.). Rigorous selection criteria were used. The findings were related to the distribution of lipoprotein concentrations in a carefully screened control population. Hyperlipoproteinaemia occurred in $55 \%$ of patients and in 11 out of 15 patients aged less than 40 years. Raised triglyceride and cholesterol concentrations in very low density lipoprotein were the most frequent abnormalities followed by raised cholesterol content of low density lipoprotein. In young patients high density lipoprotein levels were subnormal. Hyperlipoproteinaemia of W.H.O. types IIa, IIb, III, IV, and V all seemed to be over-represented in I.H.D. I.H.D. patients with type Ia, IIb, and IV abnormalities were all significantly younger than I.H.D. patients with normal lipoprotein levels.

Department of Chemical Pathology, Royal Postgraduate Medical School, London W.12

B. LEWIS, M.D., M.R.C.PATH., Senior Lecturer

I. D. P. WOOTTON, F.R.I.C., F.R.C.PATH., Professor

A. ONITIRI, M.B., CH.B., Research Assistant

A. ONITIRI, M.B., CH.B., Research Assistant

A. FEBRUARY, A.I.M.L.T., Senior Technician

Department of Clinical Cardiology, Royal Postgraduate Medical School, London W.12

C. M. O. OAKLEY, M.D., F.R.C.P., Senior Lecturer

Medical Unit, London'Hospital, London

A. CHAIT, M.SC., M.R.C.P., Lecturer

King Edward Memorial Hospital, Ealing, London

D. M. KRIKLER, M.D., F.R.C.P., Consultant Physician

\section{Introduction}

Hyperlipidaemia is a common finding in patients with ischaemic heart disease (I.H.D.), and extensive atherosclerosis may be present at an early age in the familial hyperlipidaemic states (Slack, 1969; Fredrickson and Levy, 1972). Prospective studies have shown an increased incidence of I.H.D. in patients with even mildly raised serum levels of cholesterol (Truett et al., 1967; Stamler, 1967) and triglyceride (Rosenman et al., 1970; Carlson and Böttiger, 1972).

Plasma lipids are transported in four major classes of lipoprotein, the concentrations of which determine the levels of the individual lipids (Tria and Scanu, 1969). There seem to be a number of hyperlipidaemic states, our understanding of which was greatly advanced in 1967 by a new working classification of these conditions based on assessment of lipoprotein abnormalities rather than lipid levels (Fredrickson et al., 1967).

Though there has been prolonged controversy over the relative importance of hypercholesterolaemia and hypertriglyceridaemia as risk factors for I.H.D. (Carlson and Wahlberg, 1966; Brown et al., 1972; Coronary Drug Project, 1972; Albrink, 1973; Goldstein et al., 1973) it cannot be assumed that hyperlipidaemia in ischaemic diseases results from any single metabolic disorder. The characterization of disorders of lipid metabolism in I.H.D. is of more than academic importance, for their optimal treatment, especially by drugs, differs considerably (Levy et al., 1972).

Numerous studies have been reported of the lipoprotein abnormalities in I.H.D. (Mills and Wilkinson, 1966; Tzagournis et al., 1968; Heinle et al., 1969; Dyerberg et al., 1970; Leren and Haabrekke, 1971; Gustafson et al., 1972; Patterson and Slack, 1972; Goldstein et al., 1973; Nikkila and Aro, 1973). Most have used the qualitative procedure of electrophoresis to evaluate hyperlipoproteinaemia, but most I.H.D. patients have only mildly raised lipoprotein levels which, unlike the more florid genetically determined disorders, are not readily assessed by non-quantitative methods. Analytical and preparative ultracentrifugation have been used to provide quantitative data (Mills and Wilkinson, 1966; Heinle et al., 1969).

We have recently reported a quantitative study of serum lipids and lipoproteins in a carefully screened and apparently healthy 
TABLE I-Serum Cholesterol and Triglyceride in Ischaemic Heart Disease Patients and Controls. Results expressed as Means + S.E. of Mean

\begin{tabular}{|c|c|c|c|c|c|c|c|c|}
\hline \multirow{2}{*}{ Age and Sex } & \multicolumn{3}{|c|}{ I.H.D. Patients } & \multicolumn{3}{|c|}{ Controls } & \multicolumn{2}{|c|}{ I.H.D. Values as $\%$ of Control Values $\dagger$} \\
\hline & No. & $\begin{array}{l}\text { Cholesterol } \\
(\mathrm{mg} / 100 \mathrm{ml})\end{array}$ & $\begin{array}{c}\text { Triglyceride* } \\
(\mathrm{mmol} / \mathrm{l} .)\end{array}$ & No. & $\begin{array}{l}\text { Cholesterol } \\
(\mathrm{mg} / 100 \mathrm{ml})\end{array}$ & $\begin{array}{l}\text { Triglyceride* } \\
(\mathrm{mmol} / \mathrm{l} .)\end{array}$ & Cholesterol & Triglyceride \\
\hline $\begin{array}{l}\text { Men }\left\{\begin{array}{l}26-39 \mathrm{yr} \\
40-73 \mathrm{yr}\end{array}\right. \\
\text { Women } 44-73 \mathrm{yr}\end{array}$ & $\begin{array}{r}15 \\
108 \\
20\end{array}$ & $\begin{array}{l}264 \pm 14 \\
268 \pm 5 \\
280 \pm 12\end{array}$ & $\begin{array}{l}2.27 \pm 0.013 \\
1.93 \pm 0.012 \\
1.78 \pm 0.013\end{array}$ & $\begin{array}{l}57 \\
82 \\
73\end{array}$ & $\begin{array}{l}214 \pm 4 \\
235 \pm 4 \\
245 \pm 4\end{array}$ & $\begin{array}{l}1.38 \pm 0.012 \\
1.40 \pm 0.018 \\
1.19 \pm 0.012\end{array}$ & $\begin{array}{l}123 \\
114 \\
114\end{array}$ & $\begin{array}{l}165 \\
138 \\
150\end{array}$ \\
\hline
\end{tabular}

*Triglyceride values are based on logarithmically transformed data

†All I.H.D. lipid values differ significantly from corresponding control values $(P<0.001)$.

London population (Lewis et al., 1974). Using normal ranges based upon this study we have assessed the frequency of the various forms of hyperlipidaemia in I.H.D.

The present study is part of a survey of I.H.D. in four European cities intended partly to evaluate the possibility that geographical differences exist in the relative frequency of the various risk factors (Micheli et al., 1973). Most forms of hyperlipoproteinaemia were found to be over-represented in I.H.D. patients. Using the quantitative technique of preparative ultracentrifugation we found raised levels of (in decreasing order of frequency) the triglyceride-bearing very low density lipoprotein or the cholesterol-bearing low density lipoprotein or both lipoproteins.

\section{Patients and Methods}

The series included patients who had had one or more myocardial infarction and those with angina pectoris. At least two of the following criteria were required for the diagnosis of myocardial infarction: typical history, typical E.C.G. changes, or raised serum aspartate aminotransferase or lactic dehydrogenase levels. The diagnosis of angina required a typical history with confirmatory E.C.G. changes, but many of the patients had also undergone angiography and the presence of coronary atherosclerosis was thereby confirmed.

Myocardial infarction patients were investigated at least three months after the episode to permit serum lipids to return to their preinfarct levels (Smith, 1957; Watson et al., 1963; Fyfe et al., 1971). A minority of patients were investigated after longer intervals-up to 13 months; the mean interval was 4.9 months. Patients who had minor intercurrent illnesses were not investigated until two weeks had elapsed since cessation of symptoms. To avoid influences which might have modified serum lipid and lipoprotein concentrations the following predetermined grounds for exclusion were strictly adhered to: $(a)$ a known gain in or loss of body weight of $1.5 \mathrm{~kg}$ or more in the previous month or of $3 \mathrm{~kg}$ or more since the clinical presentation of I.H.D.; (b) congestive cardiac failure or postinfarction syndrome; $(c)$ adherence to therapeutic diets or the taking of drugs known to influence serum lipid levels; (d) major acute illness other than I.H.D. or major surgery in the previous three months.

A total of 143 patients fulfilling the selection criteria were investigated. There were 123 men aged 26-73 years and 20 women aged 44-73 years. One-hundred-and-three had suffered myocardial infarction, of whom several also had angina, and 40 had angina without evidence of infarction.

Blood samples were drawn after the patients had fasted for 14 hours, and prolonged venous stasis was avoided. Serum lipids and lipoproteins and other constituents were analysed as previously described (Lewis et al., 1974). Briefly, serum lipoproteins from all patients were quantitatively separated by preparative ultracentrifugation into very low density (V.L.D.L.), low density (L.D.L.), and high density (H.D.L.) lipoprotein classes. Cholesterol and triglyceride were measured by automated procedures (Technicon N-24a, Technicon N-78; Cramp and Robertson, 1968) on extracts of whole serum and of the lipoprotein classes. Electrophoresis of lipoproteins using cellulose acetate was performed on whole serum and where indicated on V.L.D.L. and L.D.L.

Results were related to data obtained on an apparently healthy working population during the same period and using identical laboratory methods (Lewis et al., 1974). Abnormal lipoprotein patterns were classified into the six types described by the World Health Organization (Beaumont et al., 1970). Quantitative definitions were employed, however, based on the distribution of lipoprotein concentrations in sex- and age-matched subgroups of the control population. Type IIa comprised the presence of L.D.L.-cholesterol concentration exceeding the 90th percentile of the control population, while V.L.D.L.triglyceride concentration was lower than the corresponding 90th percentile. Type IIb (raised L.D.L. and V.L.D.L.) was defined as L.D.L.-cholesterol and V.L.D.L.-triglyceride levels both exceeding the 90th percentiles, while on electrophoresis the V.L.D.L. fraction had normal pre- $\beta$ mobility. In type IV (raised V.L.D.L.) V.L.D.L.-triglyceride exceeded the 90th percentile while L.D.L.-cholesterol was less than the 90th percentile.

The recognition of types III and V also required qualitative information based on the electrophoresis of serum lipoproteins and on the naked-eye appearance of serum after storage for 18 hours at $4^{\circ} \mathrm{C}$. In type III the cholesterol and triglyceride contents of the V.L.D.L. density class exceeded their 90th percentiles, and in addition the V.L.D.L. fraction had $\beta$ mobility on electrophoresis ("floating $\beta$-lipoprotein"). In type V the triglyceride content of the V.L.D.L. fraction exceeded its 90 th percentile and there was evidence of the presence of chylomicra as well as lipoprotein of pre- $\beta$ mobility-namely, floating opalescence in stored serum and lipid staining at the origin on electrophoresis.

\section{Results}

TOTAL LIPIDS

The cholesterol and triglyceride contents of serum in I.H.D. are shown in table I. They are expressed as concentrations and also as percentages of sex- and age-matched control values previously reported for a London population (Lewis et al., 1974). Mean concentrations of both lipids were greater than control values, the increase in triglyceride being more pronounced than that of cholesterol. In men with I.H.D. the degree of both hypercholesterolaemia and hypertriglyceridaemia was greater in those aged 26-39 years than in those aged 40-73 years. The pattern for women with I.H.D. was similar.

\section{LIPOPROTEINS}

Analyses of lipoproteins were expressed as percentages of mean control values for subjects of the same age group and sex (table II). Like the concentrations of total cholesterol and triglyceride abnormalities were more pronounced in younger than older men and the patterns were similar for women.

In this series of I.H.D. patients the most pronounced abnormalities were in V.L.D.L. Triglyceride, which is largely transported in V.L.D.L., showed a more than twofold increase in concentration in this lipoprotein class in young men with I.H.D. Not reported in previous studies was the comparably pronounced increase in V.L.D.L. cholesterol which contributed substantially in some patients to the total serum cholesterol. In patients aged 40 years or more V.L.D.L.-triglyceride and V.L.D.L.-cholesterol concentrations were also considerably higher than in the control population. 
TABle II-Lipids in Very Low Density, Low Density, and High Density Lipoproteins in Ischaemic Heart Disease, expressed as Percentages of Sex-and Age-matched Control Values

\begin{tabular}{|c|c|c|c|c|}
\hline \multirow{2}{*}{ Age and Sex } & \multicolumn{2}{|c|}{ V.L.D.L. $†$} & \multirow{2}{*}{$\begin{array}{c}\text { L.D.L. } \\
\begin{array}{c}\text { Cholesterol } \\
\%\end{array} \\
\end{array}$} & \multirow{2}{*}{ H.D.L. } \\
\hline & $\begin{array}{c}\text { Cholesterol } \\
\%\end{array}$ & $\underset{\%}{\text { Triglyceride }}$ & & \\
\hline $\begin{array}{l}\text { Men }\left\{\begin{array}{l}26-39 \mathrm{yr} \\
40-73 \mathrm{yr}\end{array}\right. \\
\text { Women } 44-73 \mathrm{yr}\end{array}$ & $\begin{array}{l}222 * * * \\
168 * * * \\
173^{* * *}\end{array}$ & $\begin{array}{l}239 * * * \\
176^{* * *} \\
192 * * *\end{array}$ & $\begin{array}{l}120^{* *} \\
110^{*} \\
110^{*}\end{array}$ & $\begin{array}{l}79 * * \\
95 \\
97\end{array}$ \\
\hline
\end{tabular}

Significance of difference from control value:

$* \mathbf{P}<0.05$.

$* * P<0.01$.

†Mean V.L.D.L. cholesterol and triglyceride levels based on logarithmically

transformed data.

As would be expected L.D.L. cholesterol correlated significantly with total cholesterol content of serum (men $r=+0.64$, $\mathrm{P}<0.001$; women $\mathrm{r}=+0.89, \mathrm{P}<0.001$ ). There was also a lesser correlation between V.L.D.L. cholesterol and total cholesterol concentration in men $(r=+0.46 ; P<0.001)$, but in women the correlation was not significant $(r=+0.38)$. Significantly raised levels of L.D.L. were present, notably in younger patients; in the series as a whole this was well reflected by total cholesterol concentration in serum. But in three patients L.D.L. cholesterol exceeded its 90th or 95th percentile though the total serum cholesterol did not exceed its 90th percentile. All patients with raised L.D.L. cholesterol had total serum cholesterol levels exceeding $265 \mathrm{mg} / 100 \mathrm{ml}$. Levels of serum cholesterol exceeding the 90th percentile, therefore, were in most patients an indication that L.D.L. cholesterol was raised. But in 15 patients L.D.L. cholesterol was below the 90th percentile and V.L.D.L. cholesterol was high, and in two others L.D.L. and V.L.D.L. cholesterols were below their 90th percentiles and H.D.L. cholesterol exceeded its 95 th percentile. H.D.L. showed significantly subnormal concentration in younger patients with I.H.D. and a non-significant trend to levels below those in controls in older subjects.

\section{CLASSIFICATION OF LIPOPROTEIN ABNORMALITIES}

Classification of the patterns of serum lipoprotein abnormality was based upon fully quantitative criteria in the three common disorders and by a combination of quantitative and qualitative data in the rarer forms. The classification followed was that of Fredrickson et al. (1967) as extended by the W.H.O. (Beaumont et al., 1970). The frequency of the lipoprotein patterns found is shown in table III.

TABLE III-Lipoprotein Abnormalities according to W.H.O. Classification. Frequency of each Pattern is shown as Percentage of Ischaemic Heart Disease Patients

\begin{tabular}{|c|c|c|c|c|c|c|}
\hline $\begin{array}{l}\text { Age } \\
\text { and } \\
\text { Sex }\end{array}$ & IIa & IIb & III & IV & $\mathbf{V}$ & $\begin{array}{c}\text { Total } \\
\text { Abnormal }\end{array}$ \\
\hline $\begin{array}{l}\text { Men } \\
26-39 \text { yr } \\
40-73 \text { yr } \\
\text { Women }\end{array}$ & $\begin{array}{ll} & 14 \\
20 & \\
13 & \\
& 15\end{array}$ & $\begin{array}{cc} & 9 \\
20 & \\
7 \cdot 5 & \\
& 5\end{array}$ & $\begin{array}{ll}0 & 1 \\
1 & \\
& 0\end{array}$ & $\begin{array}{ll} & 31 \\
33 & \\
30 & \\
& 35\end{array}$ & $\begin{array}{ll} & 1.5 \\
0 & \\
2 & \\
& 0\end{array}$ & $\begin{array}{ll} & 56 \\
73 & \\
53 & \\
& 55\end{array}$ \\
\hline Total & $\begin{array}{c}14 \\
(n=20)\end{array}$ & $\begin{array}{c}8 \\
(n=12)\end{array}$ & $\begin{array}{r}0.7 \\
(n=1)\end{array}$ & $\begin{array}{c}31 \\
(n=44)\end{array}$ & $\begin{array}{c}1 \cdot 4 \\
(n=2)\end{array}$ & $\begin{array}{c}55 \\
(\mathrm{n}=79)\end{array}$ \\
\hline
\end{tabular}

One or other pattern of hyperlipoproteinaemia was present in $55 \%$ of patients with I.H.D. Of 15 patients aged under 4011 had a hyperlipoproteinaemic state. "Pure" chylomicronaemia (type I) was not found. All other types in the W.H.O. classification were seen. The commonest abnormality was pre- $\beta$ hyperlipoproteinaemia (type IV), which was present in almost one-third of patients with I.H.D. (44 out of 143). The next most frequent condition was hyper- $\beta$-lipoproteinaemia (type IIa) followed by type IIb in which both $\beta$-lipoprotein and pre- $\beta$ lipoprotein levels were raised. These patterns, especially IIb, were commoner in patients with I.H.D. presenting below the age of 40 years than in older patients. One patient had the abnormal lipoprotein ("broad" or "floating" $\beta$ ) classified as type III, and two had pre- $\beta$-hyperlipoproteinaemia associated with chylomicronaemia (type V).

TABLE IV-Mean Ages ( + S.E. of Mean) of I.H.D. patients in Years in Relation to Lipoprotein Abnormalities

\begin{tabular}{|c|c|c|c|c|c|c|}
\hline & $\begin{array}{c}\text { Normal } \\
\text { Lipoproteins }\end{array}$ & II a & IIb & III & IV & $\mathbf{V}$ \\
\hline $\begin{array}{l}\text { Men } \\
\text { Women }\end{array}$ & $\begin{array}{l}55 \cdot 2 \pm 1 \cdot 2 \\
63 \cdot 2 \pm 3 \cdot 4\end{array}$ & $\begin{array}{l}50 * \pm 2 \cdot 6 \\
65 * \pm 2 \cdot 6\end{array}$ & $49 * \frac{ \pm}{65}+\frac{1}{4}$ & 61t & $\begin{array}{l}49 \pm 1 \cdot 7^{*} \\
51 \pm 2 \cdot 1\end{array}$ & 58t \\
\hline
\end{tabular}

- $P<0.001$ (Wilcoxon's test)

+ Only one or two patients were in these groups.

Further abnormalities of serum lipoproteins were seen in a few patients. One 48-year-old man with I.H.D. had raised levels of pre- $\beta$-lipoprotein and $\beta$-lipoprotein and also substantial chylomicronaemia. This uncommon pattern differs from type $\mathrm{V}$, in which $\beta$-lipoprotein levels tend to be low, and may perhaps be a particularly severe variant of type IIb in which the increase of triglyceride-bearing lipoprotein is pronounced. The triglyceride level in this patient was $496 \mathrm{mg} / 100 \mathrm{ml}$. Chylomicron-like particles may appear in serum in severe endogenous hypertriglyceridaemia (Mancini et al., 1973), and for this reason the patient was included among those with the IIb abnormality.

Five of the 143 patients with I.H.D. had raised V.L.D.L.triglyceride levels and subnormal L.D.L.-cholesterol levels which lay below the 5th percentile of the control population. It is well-recognized that serum samples with raised V.L.D.L. levels (type IV) may show low L.D.L. levels (Fredrickson and Levy, 1972), but the presence of subnormal L.D.L. with high V.L.D.L. in I.H.D. patients is of great interest. Another finding, reported previously by us in $2.5 \%$ of apparently healthy individuals, was an increase in V.L.D.L.-cholesterol concentration as a sole abnormality with normal V.L.D.L. triglyceride and normal L.D.L. and H.D.L. lipids. In five out of 108 men $(4 \cdot 6 \%)$ with I.H.D. the V.L.D.L. cholesterol exceeded the 90th percentile in this manner.

\section{AGE OF I.H.D. PATIENTS IN RELATION TO LIPOPROTEIN} ABNORMALITIES

Male I.H.D. patients with raised L.D.L. or V.L.D.L. levels or both (types IIa, IIb, and IV) were younger than male patients with normal lipoprotein levels (table IV). Of the women with I.H.D., only those with raised V.L.D.L. levels (type IV) were significantly younger than those with normal lipoproteins. The few patients with the type III and type V lipoprotein abnormalities were similar in age to the normolipoproteinaemic group. Five I.H.D. patients with a mean age ( \pm S.E. of mean) of $50 \pm 1.5$ years had subnormal L.D.L.-cholesterol levels (below 5th percentile) with raised V.L.D.L.-triglyceride levels. These were significantly younger than I.H.D. patients without lipoprotein abnormalities $(P=0.001$ by Wilcoxon's test).

\section{OTHER RISK FACTORS}

Serum uric acid concentration was higher in men aged 40-73 years with I.H.D. than in controls (mean \pm S.D. $=7 \cdot 7 \pm 1 \cdot 6 \mathrm{mg}$ / $100 \mathrm{ml}$ and $6.1 \pm 1.2 \mathrm{mg} / 100 \mathrm{ml}$ respectively; $\mathrm{P}<0.025)$ but there were no significant differences in younger men or women. Young male I.H.D. patients were more obese than controls, but differences were slight and not significant in men and women aged 40 or more. In young men the sum of three skinfold thickness measurements (mean \pm S.D.) was $59 \pm 19 \mathrm{~mm}$ in the I.H.D. group and $47 \pm 19 \mathrm{~mm}$ in controls $(P<0.025)$. Altogether 106 male patients and 11 female patients smoked cigarettes. Fasting blood glucose was higher in I.H.D. patients than in controls: 
in men concentrations (mean \pm S.E. of mean) were $84 \pm 2.0$ and $78 \pm 0.88 \mathrm{mg} / 100 \mathrm{ml}$ respectively $(P=0.002)$ and in women $89 \pm 4.4$ and $77 \pm 1.3 \mathrm{mg} / 100 \mathrm{ml}$ respectively $(P=0.001)$.

\section{Discussion}

Our data confirm that hyperlipoproteinaemia is a frequent finding in patients with ischaemic heart disease, particularly in younger patients, of whom 11 out of 15 showed a recognized lipoprotein abnormality. In one published series $68 \%$ of young patients had raised lipid levels (Tzagournis et al., 1968). The reported frequency of lipid abnormalities in I.H.D. is variable, partly because of the choice of cut-off points defining hyperlipidaemia. Of our 143 patients aged 26-73 years 55\% had hyperlipoproteinaemia as diagnosed by quantitative criteria, a percentage comparable with the range of $43 \%-57 \%$ in several published series using a variety of laboratory procedures but higher than in two extensive series in which different selection criteria were used (Goldstein et al., 1973; Patterson and Slack, 1972). There was little evident difference between the serum lipoproteins of men and women with I.H.D.

Raised levels of cholesterol, triglyceride, and of both lipids were noted. In our study the degree of hypertriglyceridaemia exceeded that of hypercholesterolaemia. This is by no means a universal finding; comparable findings have been reported in two studies in Stockholm (Carlson and Wahlberg, 1966; Enger and Ritland, 1970), in an extensive series in Seattle (Goldstein et al., 1973), and one in Los Angeles (Blankenhorn et al., 1968), but a somewhat greater preponderance of raised cholesterol was noted in Gothenburg (Gustafson et al., 1972), Glasgow (Rifkind et al., 1968), and Oslo (Leren and Haabrekke, 1971). In London Patterson and Slack (1972) found similar frequencies of hypercholesterolaemia and hypertriglyceridaemia in younger patients though hypercholesterolaemia was commoner in older female patients, and in a series of angiographically-proven I.H.D. patients in the U.S. the two lipid abnormalities were almost equally frequent (Heinle et al., 1969). The variability of these findings can be explained partly by differences in selection criteria-for example, interval between myocardial infarction and blood sampling (Smith, 1957; Watson et al., 1963; Fyfe et al., 1971) and the use of lipid-lowering drugs. The Seattle series (Goldstein et al., 1973) was based on consecutive patients. A major factor may be changes in body weight subsequent to the clinical presentation of I.H.D. for levels of serum lipids, particularly triglyceride, often decrease substantially and rapidly during weight reduction. We tried to minimize this effect by excluding patients whose known weight had changed more than slightly. Failure to observe this precaution rigorously could yield misleading frequencies of hyperlipidaemia, especially of raised triglyceride and V.L.D.L. levels. Of the patients presenting at Hammersmith Hospital with angina pectoris or being discharged after myocardial infarction about $40 \%$ qualified for inclusion in this series. Finally, the possibility exists of genuine geographical differences in the relative frequency of metabolic and other risk factors in I.H.D. patients.

There is evidence that in younger patients with I.H.D. hypercholesterolaemia is a commoner abnormality than in older patients (Patterson and Slack, 1972; Gustafson et al., 1972) and this is suggested also by our data on men.

Quantification of the lipids in the three lipoprotein classes reflected measurement of total cholesterol and triglyceride levels in serum, in that raised L.D.L. and V.L.D.L. lipids were commoner in younger than older patients, and the increase in V.L.D.L. lipids was more pronounced than that of L.D.L. lipids. A major finding in this study was the striking magnitude of the increase in V.L.D.L. cholesterol and triglyceride in I.H.D. patients selected as described. It was of interest that H.D.L. cholesterol tended to be low, particularly in young patients. Levels of this lipoprotein are often low in hyperlipoproteinaemia affecting V.L.D.L. and L.D.L. H.D.L. contains a minor proportion of plasma cholesterol and triglyceride but is important as the acceptor of free cholesterol being mobilized from tissues, and in its inherited deficiency a cholesterol storage disease develops (Fredrickson et al., 1972).

Because the hyperlipidaemic states are heterogenous the description of lipid abnormalities in I.H.D. is dependent on an adequate classification system. The distinction between plasma lipoprotein patterns as seen on qualitative electrophoresis (Fredrickson et al., 1967; Fredrickson et al., 1972) has provided a large measure of clarification of hyperlipidaemia though it does not necessarily distinguish metabolic (Lewis, 1973) or genetic entities (Goldstein et al., 1973). We used the W.H.O. extension of the original five-type classification system of Fredrickson and allocated patients to one of six types. This approach was refined by using quantitative criteria for allocation of sera to the three common types, based on measurements in a healthy population.

Apart from pure chylomicronaemia (type I) all types of hyperlipoproteinaemia were seen in patients with I.H.D. In the control population (Lewis et al., 1974) hyperlipoproteinaemia of types IIa and IV each occurred, by definition, in 10\%, type IIb was seen in 3\%, and no subject had type III or V. Therefore, all W.H.O. types except I appear to be over-represented in I.H.D. Type IV was the commonest abnormal pattern followed by types IIa and IIb. Types IIb and IIa were relatively prominent in patients under 40 years of age. In the series as a whole, however, increased concentration of triglyceride in V.L.D.L. was commoner than increased concentration of cholesterol in L.D.L.

The significance of hypertriglyceridaemia in I.H.D. has long been a subject of controversy since the association was reported by Albrink and Man (1959), Carlson (1960), and Antonis and Bersohn (1960). Raised triglyceride levels were interpreted to be an independent risk factor for I.H.D. in two recent prospective surveys (Carlson and Böttiger, 1972; Rosenman et al., 1970), but not in others (Brown et al., 1972; Coronary Drug Project, 1972). In the retrospective Seattle survey by Goldstein et al. (1973), which showed a substantially greater frequency of hypertriglyceridaemia than hypercholesterolaemia, it was reported that the relatives of I.H.D. patients with hyperlipidaemia more often showed hypertriglyceridaemia than hypercholesterolaemia. Patterson and Slack (1972) have found that hypertriglyceridaemia is commoner than hypercholesterolaemia in the relatives of hyperlipidaemic survivors of myocardial infarction, but this preponderance seemed to be no greater than that in the control population.

I.H.D. patients with certain lipoprotein abnormalities were significantly younger than I.H.D. patients with normal lipoprotein concentrations. I.H.D. seemed to present earlier in men with raised L.D.L. concentration or with increased L.D.L. and V.L.D.L. levels and in both men and women with increased V.L.D.L. concentrations. In five patients the presence of raised V.L.D.L. levels was associated with a significantly younger age of presentation despite subnormal L.D.L.-cholesterol concentrations. Our study does not directly resolve the issue of whether hypertriglyceridaemia is or is not an independent risk factor for I.H.D. or whether it may be additive to the unarguable role of hypercholesterolaemia (Truett et al., 1967; Stamler, 1967; Rosenman et al., 1970; Carlson and Böttiger, 1972). There are no grounds for the assumption that one or other form of hyperlipidaemia is uniquely associated with atherosclerotic heart disease. The accumulated evidence suggests, we believe, that at licast in some communities more than one type of hyperlipoproteinaemia may play a role in the pathogenesis of I.H.D. A possible unifying concept would be that the cholesterol content of V.L.D.L. as well as that of L.D.L. plays a role in atherogenesis.

A few I.H.D. patients had lipoprotein abnormalities not conforming to W.H.O. (Beaumont et al., 1970) definitions. One man had fasting chylomicronaemia as well as raised V.L.D.L. triglyceride and L.D.L. cholesterol and five had raised V.L.D.L.cholesterol levels though V.L.D.L.-triglyceride was normal. Raised levels of total serum cholesterol were most often due to an increase in its L.D.L.-borne component, but in two men they were owing to H.D.L.-cholesterol levels exceeding the 99th 
percentile. There is no evidence that raised H.D.L. levels are significant in relation to atherosclerosis. In 15 patients total serum cholesterol exceeded its 95 th percentile due to high V.L.D.L.-cholesterol levels, the L.D.L. cholesterol being normal or low.

We thank Professors J. Shillingford and J. F. Goodwin for permitting us to study patients under their care. The study was supponted by grants from the Medical Research Council and from Unilever Ltd. We thank Miss A. Petrie and Mr. John Dolan for help with statistical analyses and data processing.

\section{References}

Albrink, M. J., and Man, E. B. (1959). Archives of Internal Medicine, 103, 4 Albrink, M. J. (1973). Fournal of the American Dietetic Association, 62, 626. Antonis, A., and Bersohn, I. (1960). Lancet, 1, 998.

Beaumont, J. L. et al. (1970). Bulletin of the World Health Organization, 43, 891.

Blankenhorn, D. H., Chin, H. P., and Lau, F. Y. K. (1968). Annals of Internal Medicine, 69,21

Brown, D. F., Kinch, S. H., and Doyle, S. T. (1972). New England fournal of Medicine, 273, 947.

Carlson, L. A. (1960). Acta Medica Scandinavica, 167, 399.

Carlson, L. A., and Wahlberg, F. (1966). Acta Medica Scandinavica, 180, 307. Carlson, L. A., and Böttiger, L. E. (1972). Lancet, 1, 865.

Coronary Drug Project (1970). Fournal of the American Medical Association, 220, 996.

Cramp, D. G., and Robertson, G. (1968). Analytical Biochemistry, 25, 246.

Dyerberg, J., Bang, H. O., and Nielsen, J. A. (1970). Acta Medica Scandinavica, 187, 353 .
Enger, S. C., and Ritland, S. (1970). Acta Medica Scandinavica, 187, 365.

Fredrickson, D. S., Levy, R. I., and Lees, R. S. (1967). New England fournal of Medicine, 276, 34, 94, 148, 215, and 273

Fredrickson, D. S., and Levy, R. L. (1972). In Metabolic Basis of Inherited Disease, ed. J. B. Stanbury, J. B. Wyngaarden, and D. S. Fredrickson, 3rd edn. New York, McGraw-Hill.

Fredrickson, D. S., Gotto, A. M., and Levy, R. I. (1972). In Metabolic Basis of Inherited Disease, ed. J. B. Stanbury, J. B. Wyngaarden, and D. S. Fredrickson, 3rd edn., p. 493. New York, McGraw-Hill.

Fyfe, T., et al. (1971). Lancet, 2, 997.

Goldstein, J. L., et al. (1973). Fournal of Clinical Investigation, 52, 1533.

Gustafson, A., et al. (1972). Circulation, 46, 709.

Gustafson, A., et al. (1972). Circulation, 46, 709. in Lipid Research, $6,1$.

Hatch, F. T., and Lees, R. S. (1968). Advances in Lipid Research, 6,

Heinle, R. A., et al. (1969). American fournal of Cardiology, 24, 178.

Leren, P., and Haabrekke, O. (1971). Acta Medica Scandinavica,

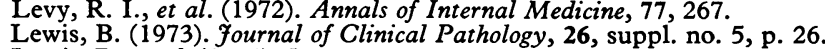

Lewis, B., et al. (1974). Lancet, 1, 141.

Mancini, M., et al. (1973). Atherosclerosis, 17, 445.

Micheli, H., et al. (1973). European fournal of Clinical Investigation, 3, 255.

Mills, G. L., and Wilkinson, P. A. (1966). British Heart fournal, 28, 638.

Nikkilä, E. A., and Aro, A. (1973). Lancet, 1, 954.

Patterson, D., and Slack, J. (1972). Lancet, 1, 393.

Rifkind, B. M., Lawson, D., and Gale, M. (1968). Fournal of Atherosclerosis Research, 8, 167.

Rosenman, R. H., et al. (1970). Fournal of Chronic Diseases, 23, 173.

Slack, J. (1969). Lancet, 2, 1380

Smith, E. B. (1957). Lancet, 2, 910.

Stamler, J. (1967). Lectures on Preventive Cardiology. New York, Grune and Stratton.

Tria, E., and Scanu, A. M. (1969). Structural and Functional Aspects of Lipoproteins in Living Systems. London and New York, Academic Press.

Truett, J., Cornfield, J., and Kannel, W. B. (1967). Fournal of Chronic Diseases, 20, 511

Tzagournis, M., et al. (1968). Circulation, 38, 1156.

Watson, W. C., Buchanan, K. D., and Dickson, C. (1963). British Medical Fournal, 2, 709.

\title{
Insulin Secretion in Malignant Hyperpyrexia
}

\author{
M. A. DENBOROUGH, \\ G. L. WARNE, \\ R. F. W. MOULDS, \\ P. TSE, F. I. R. MARTIN
}

British Medical fournal, 1974, 3, 493-495

\section{Summary}

An increased glucose-induced insulin response has been observed in patients susceptible to malignant hyperpyrexia. This raises the possibility that the membrane abnormality present in the calcium-storing membranes in the muscle cell in malignant hyperpyrexia may be present also in the beta cell of the pancreas.

\section{Introduction}

The syndrome of malignant hyperpyrexia is caused by a raised level of calcium ions in the myoplasm (Britt and Kalow, 1970; Denborough et al., 1973) which results from a rapid increased release of calcium from the calcium-storing membranes in the muscle cells of affected subjects, when exposed to general anaesthetics (Moulds and Denborough,

\footnotetext{
Department of Medicine, University of Melbourne, Melbourne, Australia

M. A. DENBOROUGH, M.D., F.R.A.C.P., Reader in Medicine (Present address: Department of Clinical Science, Australian National University, Canberra Hospital, Canberra, A.C.T. 2601, Australia)

F. I. R. MARTIN, M.D., F.R.A.C.P., Endocrinologist

R. F. W. MOULDS, B.MED.SCI., M.R.A.C.P., Research Fellow

G. L. WARNE, M.B., M.R.A.C.P., Assistant Endocrinologist

Department of Clinical Biochemistry, Royal Melbourne Hospital, Melbourne, Australia

P. TSE, M.sc., Biochemist
}

1974). The question arises whether other calcium-storing membranes in the body might be involved.

The work of Malaisse et al. has suggested that the regulation of insulin secretion depends on the level of calcium in the beta cells of the pancreas (Malaisse and Malaisse-Lagae, 1970), and these workers have drawn an analogy between the role of calcium in the release of insulin and its role in excitation-contraction coupling in muscle (Malaisse, 1973). This has prompted us to examine glucose-stimulated insulin secretion in patients with the myopathy predisposing to malignant hyperpyrexia.

\section{Subjects and Methods}

Intravenous glucose tolerance tests (G.T.T.) (glucose 0.75 $\mathrm{g} / \mathrm{kg}$ body weight to a maximum of $50 \mathrm{~g}$ ) were performed after overnight fasting on 13 patients who were susceptible to malignant hyperpyrexia and on 10 controls. The patients (who included three survivors from malignant hyperpyrexia) were identified by showing in vitro a highly abnormal sensitivity of the calcium-storing membranes in their muscle cells to halothane, suxamethonium, caffeine, and potassium chloride (Moulds and Denborough, 1974). Five of the controls were related to patients with malignant hyperpyrexia but their muscle gave a normal response to in-vitro pharmacological testing and they were considered to be unaffected by the disease; the other five were apparently healthy volunteers.

No subject was diabetic and only one myopathic patient was obese. All were receiving normal diets before testing and no one was taking other drugs. Only one subject, a healthy volunteer, gave a family history of diabetes. The 